\title{
Diversidade Genética de Begomovirus gue Infectam Plantas INVASORAS NA REGIÃO NORDESTE ${ }^{1}$
}

\author{
Genetic Diversity of Begomovirus Infecting Weeds in Northeastern Brazil
}

\author{
ASSUNÇÃO, I.P. ${ }^{2}$, LISTIK, A.F. ${ }^{2}$, BARROS, M.C.S. ${ }^{2}$, AMORIM, E.P.R. ${ }^{2}$, SILVA, S.J.C. ${ }^{2}$, \\ IZAEL, O. SILVA², RAMALHO-NETO, C.E. ${ }^{2}$ e LIMA, G.S.A. ${ }^{3}$
}

\begin{abstract}
RESUMO - Os Begomovirus fazem parte de uma família numerosa de fitovírus denominada Geminiviridae. Eles infectam ampla gama de hospedeiras, incluindo muitas espécies cultivadas, como tomate (Lycopersicon esculentum), feijão (Phaseolus vulgaris), pimentão (Capsicum annuum), caupi (Vigna unguiculata), mandioca (Manihot esculenta) etc., além de plantas invasoras de várias espécies. Em alguns casos, plantas invasoras podem funcionar como reservatórios desses vírus para plantas cultivadas, mediante transmissão pelo insetovetor. No presente trabalho, plantas invasoras com sintomas de mosaico amarelo, deformação do limbo foliar e redução do crescimento foram avaliadas no tocante à presença de Begomovirus mediante a técnica de PCR, empregando-se oligonucleotídeos universais para detecção desses vírus. Foram avaliadas 11 amostras, correspondendo a 10 espécies, coletadas em municípios dos Estados de Alagoas, Pernambuco e Bahia. Algumas, como Herissantia crispa, Waltheria indica e Triumfetta semitriloba, são relatadas pela primeira vez como espécies hospedeiras de Begomovirus. Para estimar a variabilidade genética dos Begomovirus detectados, o produto de amplificação dos diversos isolados foi clivado com as enzimas de restrição EcoRI, Hinfl e TaqI. Confirmando resultados obtidos para plantas cultivadas por outros grupos de pesquisa, foram observados padrões distintos de clivagem para os isolados estudados, evidenciando a grande variabilidade genética desses vírus.
\end{abstract}

Palavras-chave: geminiviridae, detecção, PCR, hospedeiras daninhas.

\begin{abstract}
Genus Begomovirus belong to the family Geminiviridae. Begomovirus is associated with a wide range of hosts, including many cultivated species such as tomato (Lycopersicon esculentum), dry beans (Phaseolus vulgaris), pepper (Capsicum annuum), cowpea (Vigna unguiculata), cassava (Manihot esculenta), etc., besides many weed species. It has been demonstrated that in some cases weeds act as virus reservoirs for cultivated plants. In the present work, weed samples presenting yellow mosaic, foliar malformation and size reduction were tested by PCR for infection by Begomovirus, using specific degenerate oligonucleotides. Eleven samples corresponding to 10 plant species were collected in the countryside towns in the states of Alagoas, Pernambuco and Bahia. Some plant species such as Herissantia crispa, Waltheria indica and Triumfetta semitriloba are reported for the first time as hosts for Begomovirus. To estimate the genetic diversity of the detected Begomovirus, the amplified products of several isolates were cleaved with each three restriction enzymes, EcoRI, HinfI, and TaqI. Different patterns were observed for the studied isolates, pointing out to a great genetic diversity for these viruses.
\end{abstract}

Keywords: geminivirus, PCR detection, weed hosts, restriction enzymes.

Recebido para publicação em 11.8.2005 e na forma revisada em 5.5.2006.

Departamento de Fitotecnia e Fitossanidade, Universidade Federal de Alagoas, Campus Delza Gitaí, BR 104 Norte, Km 85, 571000-000 Rio Largo-AL. ${ }^{3}$ Departamento de Botânica, Centro de Ciências Biológicas, Universidade Federal de Alagoas, Praça Afrânio Jorge, s/n, Prado, 57010-020 Maceió-AL.

Planta Daninha, Viçosa-MG, v. 24, n. 2, p. 239-244, 2006 


\section{INTRODUÇÃO}

Os Begomovirus estão classificados na família Geminiviridae e constituem atualmente um dos principais problemas fitossanitários de muitas culturas agrícolas em todo o mundo. Perdas significativas, em decorrência da incidência das geminiviroses, têm sido relatadas, entre outros, em plantios de tomate, feijão, caupi, mandioca, pimentão e algodão (Faria et al., 2000; Morales \& Anderson, 2001).

Os Begomovirus caracterizam-se por apresentar "partículas geminadas" com morfologia icosaédrica e genoma composto, na maioria das vezes, por duas moléculas de DNA circular de fita simples (Lazarowitz, 1992), denominadas DNA-A e DNA-B, cada uma com aproximadamente 2.500 nucleotídeos. Outras características importantes são dicotiledôneas em suas gamas de hospedeiras e "moscas-brancas", como seu inseto-vetor (Bemisia tabaci) (Faria et al., 2000).

As geminiviroses vêm sendo relatadas no Brasil desde a década de 1930. No entanto, apenas no início da década de 1980 se tornaram economicamente importantes, causando perdas elevadas em culturas de várias espécies de plantas cultivadas. Aparentemente, o aumento da incidência das viroses ocasionadas por Begomovirus está relacionado ao surgimento e à disseminação de um novo biótipo (biótipo B) da "mosca-branca" (Faria et al., 2000). O biótipo B transmite os vírus mais eficientemente e apresenta uma gama de hospedeiros mais ampla que o biótipo A. Além disso, populações do biótipo $\mathrm{B}$ resistentes a inseticidas são mais rapidamente selecionadas que no biótipo A (Faria et al., 2000). Esses fatos dificultam sobremaneira o controle das "moscas-brancas" e, conseqüentemente, das doenças causadas por Begomovirus.

Além de plantas cultivadas, muitas espécies de plantas invasoras têm sido relatadas como hospedeiras de Begomovirus em vários países, inclusive no Brasil. As espécies relatadas geralmente pertencem a Malvaceae, Euphorbiaceae e Fabaceae (Morales \& Anderson, 2001). Alguns estudos demonstraram casos em que Begomovirus provenientes de plantas invasoras podem ser transmitidos para espécies cultivadas através do inseto-vetor ou mediante inoculação via extrato vegetal tamponado (Frischmuth et al., 1997; Faria et al., 2000; Morales \& Anderson, 2001). Dados convincentes indicam que plantas invasoras podem funcionar como fontes de inóculo de Begomovirus para plantas cultivadas e que a erradicação dessas plantas das áreas de cultivo deve ser uma medida adotada visando a redução da incidência dessas viroses.

No Brasil, já se realizaram estudos objetivando caracterizar molecularmente isolados de geminivírus que infectam plantas cultivadas, sobretudo o feijoeiro e o tomateiro (Faria \& Maxwell, 1999; Ribeiro et al., 1998; Cotrim et al., 2004). Os resultados desses estudos revelam enorme variabilidade genética entre os isolados. Resultados prévios indicam que, a exemplo do que ocorre com plantas cultivadas, a variabilidade é muito grande entre os Begomovirus que infectam plantas invasoras (Ambrozevicius et al., 2002; Callegario et al., 2004).

A caracterização de Begomovirus que infectam plantas invasoras é a etapa inicial para se chegar a importantes informações sobre aspectos ecológicos e evolutivos a respeito desses vírus. Poderá também contribuir para elucidar se esses isolados podem infectar plantas cultivadas de importância para a região Nordeste, como tomate, feijão, pimentão e caupi. O presente trabalho teve como objetivos verificar a ocorrência de Begomovirus em diversas espécies de plantas invasoras provenientes dos Estados de Alagoas, Pernambuco e Bahia e estudar a variabilidade genética dos isolados detectados mediante PCR-RFLP (Polymerase Chain Reaction - Restriction Fragment Length Polymorphism).

\section{MATERIAL E MÉTODOS}

Amostras de plantas invasoras apresentando mosaico amarelo, deformação do limbo foliar e redução do crescimento (Figura 1) foram coletadas em municípios de Alagoas, Bahia e Pernambuco (Tabela 1). De modo geral, foram coletados ramos férteis com folhas novas. Os ramos férteis foram enviados aos Laboratórios de Botânica da Empresa Pernambucana de Pesquisa Agropecuária IPA, Recife, PE, ou da Universidade Federal de Alagoas - UFAL, Maceió, AL, para identificação 
botânica. Amostras de tecidos foliares jovens foram levadas ao Laboratório de Fitopatologia da UFAL, para extração de DNA. Foram coletadas 11 amostras, de março de 2003 a julho de 2004.

As extrações de DNA de plantas possivelmente infectadas por geminivirus foram realizadas segundo método descrito por Ferreira \& Grattapaglia (1995). Aproximadamente $30 \mathrm{ng}$ do DNA extraído foram utilizados como molde para o teste de PCR contendo os pares de oligonucleotídeos PAL1v1978/par1C496 ou PBL1v2040/PCRc1, visando amplificar, respectivamente, regiões específicas do DNA-A e DNA-B do genoma dos Begomovirus (Rojas et al., 1993). O controle positivo da PCR consistiu em reações de amplificação contendo plasmídeos com fragmentos do DNA A e B do genoma do Sida golden mosaic virus,

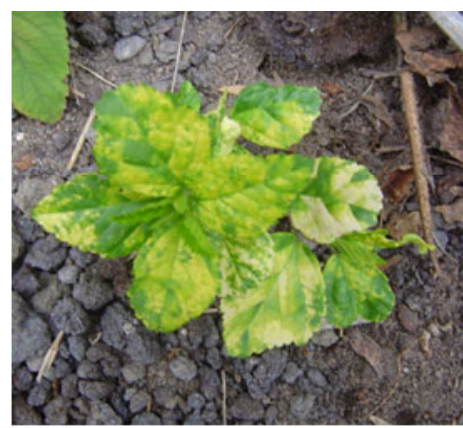

Sida rhombifolia

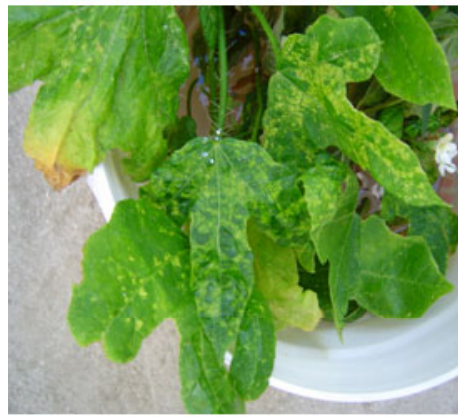

Cnidoscolus urens

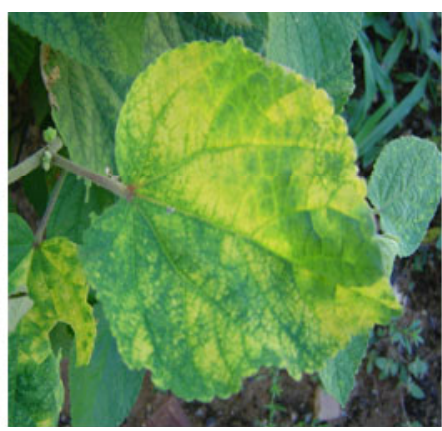

Sidastrum micrantum

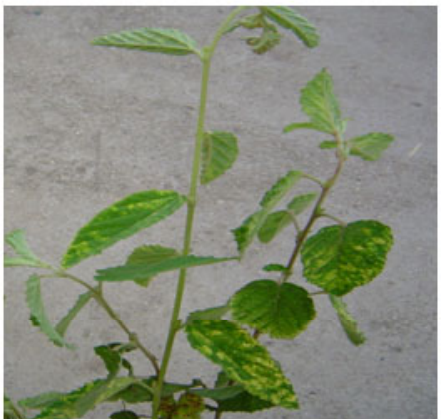

Waltheria indica

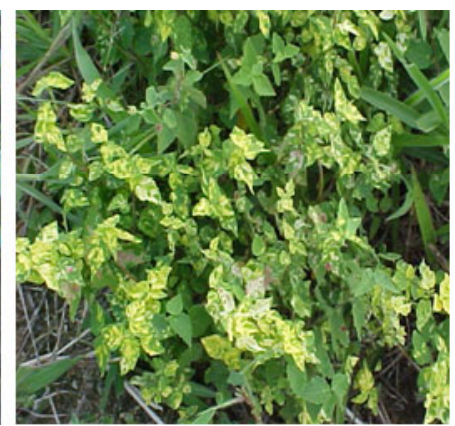

Herissantia crispa

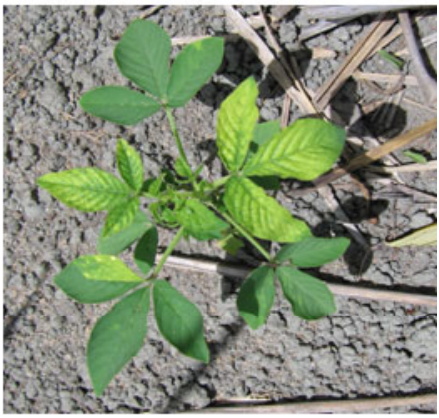

Cleome affinis

Figura 1 - Sintomas de mosaico provocados por Begomovirus em algumas plantas invasoras estudadas neste trabalho.

Tabela 1 - Procedência das plantas invasoras infectadas com Begomovirus utilizadas neste estudo

\begin{tabular}{|c|c|c|c|}
\hline Nome popular & Nome científico & Família & Procedência \\
\hline Malva-guaxuma & Sida rhombifolia $\mathrm{L}$. & Malvaceae & Rio Largo - AL \\
\hline Mela-bode & Herissantia crispa (L.) Brizicky & Malvaceae & Maceió - AL \\
\hline Mela-veludo & Sidastrum micranthum (St.-Hil.) Fryxel & Malvaceae & Maceió - AL \\
\hline Carrapicho & Triumfetta semitriloba Jacq. & Sterculiaceae & Tamandaré - PE \\
\hline Malva & S. spinosa L. & Malvaceae & Maceió - AL \\
\hline Mussambê & Cleome affinis D.C. & Capparaceae & Maceió - AL \\
\hline Mussambê & C. affinis D.C. & Capparaceae & Recife - PE \\
\hline Malva-sedosa & Waltheria indica $\mathrm{L}$. & Sterculiaceae & Maceió - AL \\
\hline Feijão-de-rolinha & Macroptillium lathyroides (L.) Urban & Fabaceae & Juazeiro - BA \\
\hline Carrapicho & Desmodium sp. & Fabaceae & Maceió - AL \\
\hline Cansanção & Cnidoscolus urens (L.) Arthur & Euphorbiaceae & Marechal Deodoro - AL \\
\hline
\end{tabular}


caracterizado por Lima et al. (2002) como DNA molde. Como controle negativo, o DNA molde foi extraído de plantas jovens sadias de algumas espécies estudadas. As condições das reações foram as mesmas utilizadas por Rojas et al. (1993).

Para estimar a diversidade genética, os produtos amplificados a partir do DNA-A dos diversos isolados foram clivados a seguir com as enzimas de restrição EcoRI, Hinf I e TaqI. As misturas para a clivagem dos fragmentos constituíram-se de $20 \mathrm{U}$ da enzima, $2 \mu \mathrm{L}$ do respectivo tampão $10 \mathrm{X}$, aproximadamente 200 ng do produto de PCR (5 $\mu \mathrm{L})$ e água estéril suficiente para $20 \mu \mathrm{L}$. As misturas foram incubadas durante duas horas a $37^{\circ} \mathrm{C}$ (EcoRI e Rsal) ou a $65^{\circ} \mathrm{C}$ (TaqI).

\section{RESULTADOS E DISCUSSÃO}

Todas as amostras foliares com mosaico amarelo, deformação do limbo foliar e redução do crescimento apresentavam-se infectadas com Begomovirus, visto que fragmentos de amplificação com tamanhos esperados foram observados apenas nas amostras contendo DNA de plantas sintomáticas e não nos controles assintomáticos. Quando utilizados os oligonucleotídeos PAL1v1978/par1C496, um fragmento de aproximadamente $1,2 \mathrm{~kb}$ foi amplificado nas amostras com DNA de plantas sintomáticas (dados não mostrados), ao passo que PBL1v2040/PCRc1 direcionaram, conforme esperado, à amplificação de um fragmento de cerca de $0,6 \mathrm{~kb}$ (dados não mostrados). Os pares de oligonucleotídeos PAL1v1978/ par1C496 e PBL1v2040/PCRc1 são "degenerados" (Rojas et al., 1993) e considerados universais para a detecção de Begomovirus de genoma bipartido.

As 10 espécies de plantas invasoras constatadas como hospedeiras de Begomovirus neste trabalho estão distribuídas em cinco famílias botânicas. H. crispa, W. indica, T. semitriloba e Demodium sp. ainda não haviam sido relatadas como hospedeiras desses vírus no Brasil e no mundo. Contudo, em espécies como M. latyroides, S. rhombifolia, E. heterophylla, Cleome spp., B. rhomboidea e C. urens (sinonimia Jatropha urens), a infecção por Begomovirus tem sido freqüentemente relatada. Esses resultados ampliam ainda mais as gamas de hospedeiras conhecidas para
Begomovirus, consideradas como das mais amplas entre os fitovírus e que até então incluíam aproximadamente 120 espécies de plantas de diversas famílias botânicas (van Regenmortel et al., 2000).

No Brasil, desde a década de 1940 vêm sendo relatadas infecções de plantas invasoras por geminivírus. Contudo, a importância dessas plantas como reservatórios de vírus que infectam plantas cultivadas não tem recebido muita atenção. Costa \& Carvalho (1960) relataram que o Abutilon mosaic virus (que ocorria em malváceas) e o Euphorbia mosaic virus (EuMV) (obtido de Euphorbia prunifolia) podiam ser transmitidos para o tomateiro, utilizando-se o inseto-vetor. Em condições experimentais, Frischmuth et al. (1997) demonstraram que o Sida golden mosaic virus (SiGMV) pode ser transmitido por "moscasbrancas" para feijoeiros. Pesquisa recente conduzida por Cotrim et al. (2004) determinou que cerca de $10 \%$ das amostras de tomateiros com sintomas de mosaico coletadas na região Centro-Oeste do Estado de São Paulo estavam infectadas com o Sida mottle virus (SiMoV), enquanto Callegario et al. (2004), em Minas Gerais, verificaram infecção natural do tomateiro com um isolado do Sida micrantha mosaic virus (SimMV).

No presente trabalho, a clivagem com diferentes endonucleases dos produtos de PCR amplificados a partir do DNA-A dos isolados de Begomovirus revelou grande diversidade entre os isolados estudados (Figura 2). A clivagem com EcoRI resultou no mesmo perfil de bandas para os dois isolados de C. affinis provenientes de Maceió e Recife (Figura 2A). O mesmo padrão também foi observado para os fragmentos dos isolados de $M$. latyroides, S. spinosa e W. indica (Figura 2A).

Os resultados obtidos na clivagem com TaqI são consistentes com os obtidos com a endonuclease EcoRI, indicando haver variabilidade entre os isolados estudados (Figura 2B). Os fragmentos de alguns isolados (M. latyroides, C. affinis/Maceió e C. affinis/Recife) aparentemente não apresentam o sítio de reconhecimento para TaqI, pois o produto de PCR não teve seu tamanho alterado após a incubação com a enzima (Figura 2B). Constatou-se novamente a similaridade entre os dois isolados de C. affinis. 
A

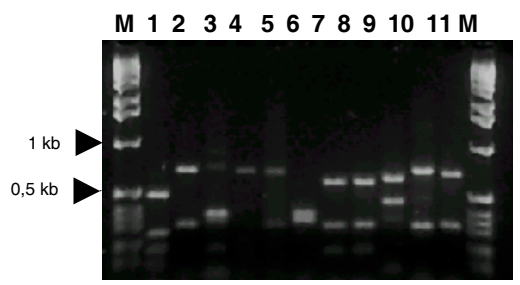

B

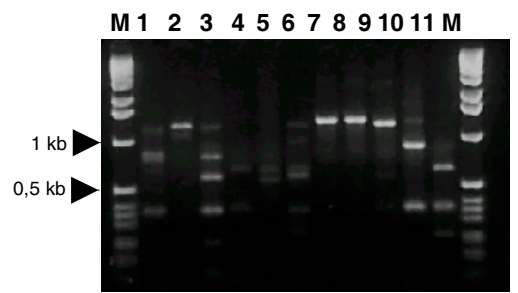

C

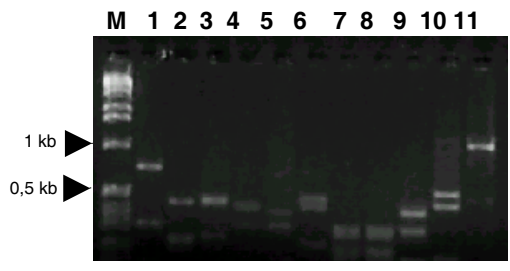

Figura 2 - Fragmentos de DNA visualizados em gel de agarose após digestão com diferentes enzimas de restrição dos produtos amplificados a partir do DNA-A de Begomovirus. A, B e C = clivagens com EcoRI, TaqI e HinfI, respectivamente; M = $1 \mathrm{~kb}$ DNA ladder; 1 = Desmodium sp.; 2 = Macroptillium lathiroides; 3 = Sidastrum micrantum; 4 = Herissantia crispa $; 5=$ Sida spinosa $; 6=$ Triumfetta semitriloba $; 7=$ Cleome affinis/Recife; $8=$ C. affinis $/$ Maceió; $9=$ Sida rhombifolia $; 10=$ Cnidoscolus urens; e $11=$ Waltheria indica.

A clivagem dos produtos de PCR dos diversos isolados com Hinfl corrobora o estreito relacionamento entre os dois isolados provenientes de C. affinis, os quais mais uma vez exibiram o mesmo padrão de bandas (Figura 2C). Nos demais isolados foram observados padrões de restrição únicos, constituídos de duas ou três bandas, o que indica existir, respectivamente, um ou dois sítios de clivagem para Hinfl no produto de amplificação (Figura 2C). A exceção foi o isolado de W. indica/Maceió, aparentemente sem qualquer sítio de clivagem para essa enzima.

Quando não se dispõe de seqüências do genoma, a clivagem de produtos de PCR com endonucleases de restrição (PCR-RFLP) tem sido muito utilizada para estimar a diversidade genética de Begomovirus (Ambrozevicius et al., 2000; Fernandes, 2002; Rojas et al., 1993) e de outros fitopatógenos. No entanto, essa técnica considera apenas o sítio de reconhecimento da enzima - uma seqüência de quatro ou seis bases, dependendo da enzima. Dessa forma, permanece indetectada qualquer alteração fora dessa região. O seqüenciamento total ou parcial do genoma dos isolados estudados seria muito mais informativo.

Em conjunto, os padrões de clivagem gerados com as três enzimas de restrição evidenciam a grande variabilidade genética entre os isolados de Begomovirus provenientes de plantas invasoras, pois praticamente cada isolado apresentou padrão próprio. A alta variabilidade genética dos Begomovirus se reflete no grande número de espécies descritas (van Regenmortel et al., 2000), o que, na prática, dificulta a adoção das medidas de controle, de eliminação de hospedeiras alternativas e a utilização de variedades resistentes, esta a medida considerada a mais adequada para o controle de fitoviroses.

\section{LITERATURA CITADA}

AMBROZEVICIUS, L. P. et al. Genetic diversity of Begomovirus infecting tomato and associated weeds in Southeastern Brazil. Fitopatol. Bras., v. 27, n.4, p. 372-377, 2002.

CALEGARIO, R. F. et al. Caracterização de um isolado do Begomovirus Sida micrantha virus (SimMV) obtido de tomateiro. Fitopatol. Bras., v. 29, p. S150, 2004.

COSTA, A. S.; CARVALHO, A. M. Comparative studies between Abution and Euphorbia mosaic viruses.

Phytopathol. Zeitsch., v. 38, n. 2, p. 129-152, 1960.

COTRIM, M. A. A. et al. Análise da diversidade genética de Begomovirus em tomateiro no Centro-Oeste Paulista. Fitopatol. Bras., v. 29, p. S109, 2004.

FARIA, J. C.; MAXWELL, D. P. Variability in geminivirus isolates associated with Phaseolus spp. In Brazil. Phytopathology, v. 89, n. 3, p. 262-268, 1999.

FARIA, J. C. et al. Situação atual das geminiviroses no Brasil. Fitopatol. Bras., v. 25, n. 2, p.125-137, 2000.

FERNANDES, J. J. Identificação e caracterização biológica e molecular de Begomovirus infectando tomateiro na região do Triângulo Mineiro. 2002. $123 \mathrm{f}$. Tese (Doutorado em Fitopatologia) - Universidade Federal de Viçosa, Viçosa, 2002. 
FERREIRA, M. E.; GRATTAPAGLIA, D. Introdução ao uso de marcadores moleculares em análise genética. 3.ed. Brasília: Embrapa-Cenargen, 1995. 220 p.

FRISCHMUTH, T. et al. Nucleotide sequence evidence for the occurrence of three distinct whitefly-transmitted Sidainfecting bipartite geminiviruses in Central America. J. General Virol., v. 78, n. 10, p. 2675-2682, 1997.

LAZAROWITZ, S. G. Geminiviruses: genome structure and gene function. Crit. Rev. Plant Sci., v. 11, p. 327-349, 1992.

LIMA, G. S. A. et al. Detecção de Begomovirus associados a plantas invasoras no Estado de Pernambuco e caracterização molecular parcial de um isolado de Sida rhombifolia.

Summa Phytopathol., v. 28, n. 4, p. 353-356, 2002.
MORALES, F. J.; ANDERSON, P. K. The emergence and dissemination of whitefly-transmitted geminiviruses in Latin America. Arch. Virol., v. 146, n. 3, p. 415-441, 2001.

RIBEIRO, S. G. et al. Widespread occurrence of tomato geminiviruses in Brazil, associated with the new biotype of the whitefly vector. Plant Disease, v. 82, n. 7, p. 830, 1998.

ROJAS, M. R. et al. Use of degenerate primers in the polymerase chain reaction to detect whitefly-transmitted geminiviruses. Plant Disease, v. 77, n. 4, p. 340-347, 1993.

van REGENMORTEL, M. H. V. et al. (Eds.). Virus taxonomy. Classification and nomenclature of viruses. In: REPORT OF THE INTERNATIONAL COMMITTEE ON THE TAXONOMY OF VIRUSES, 7., 2000, New York. Report... New York: Academic Press, 2000. 985 p. 